\title{
Zinc Supplements - Any Benefit in Diabetes?
}

Télessy IG* PharmD, PhD

Department of Pharmaceutics, University of Pécs, Hungary

*Corresponding author: István G Télessy, Assoc.Prof. University of Pécs, Dept. of Pharmaceutics, Pécs, 7624, Honvéd u. 3. and MedBioFit Lpt. Gödöllő, 2100 , Fácán sor 25. Hungary; E-mail: telessyist@vnet.hu

Received: May 23, 2019; Accepted: June 21, 2019; Published: July 05, 2019;

\begin{abstract}
Zinc is a divalent cation mainly present intracellularly and exerts several indispensible effect therefore maintaining zinc homeostasis is essential. Zinc has a pivotal role in the insulin production, storage and pathways and in carbohydrate metabolism. Plays also an important function in the development of diabetes mellitus and diabetic complications as well. Based on preclinical and clinical studies here we present the most important contributions of zinc to diabetic state and briefly demonstrate why zinc supplementation is beneficial for diabetic patients.
\end{abstract}

Keywords: Zinc, Supplementation, Diabetes mellitus

\section{Introduction}

Zinc $(\mathrm{Zn})$ is the third abundant bivalent cation in the human body, after calcium. $\mathrm{Zn}$ is found $99,8 \%$ intracellularly. It is part of several hundreds of enzymes and of ca. two thousand cofactors. Stored mainly in skeletal muscle and brain neurones. Zn plays very important role in cognitive functions and learning, in cell proliferation, in immun system, the physical development of infants and children, the skin, the metabolic processes, etc. Unfortunately, plasma zinc is insensitive to early zinc deficit and detection of hypozincemia is not a routin process. Zinc deficiency produce a myriad of symptoms but non of them is typical for the $\mathrm{Zn}$ deficit. However, as an ubiquitous trace elemet, zinc has a role in the carbohydrate metabolism and its regulation as well. Diabetes mellitus (DM) is a disease based on absolute or relative insulin deficiency with subsequent disturbances in carbohydrate metabolism. DM exists in two basic forms like type I and type II diabetes (T1DM and T2DM, respectively). Although the two types of diabetes are totally different from ethiology point of view there are numerous well defined and similar $\mathrm{Zn}$ effects in both T1DM and T2DM. Hypozincemia and hyperzincuria is part of the typical clinical symptoms of both DM forms therefore control of $\mathrm{Zn}$ deficiency in diabetic patients is necessary [1].

In the present compilation we briefly demonstrate some facts and rational considerations about use of zinc supplementation in diabetes patients.

\section{Preclinical Experiences}

\section{Pancrease Beta-Cell Stimulation}

Zinc exert a dual effect in beta-cells: via direct effect $\mathrm{Zn}$ is increasing of free insulin concentration near to beta cells besides it has an inhibitory effect on glucose stimulated insulin secretion. Transient elevation of se-glucose concentration increase free cytosolic Zn levels facilitating insulin storage, but chronic high intracellular zinc concentration resuling in beta cell dysfunction, in the extreme also cell death. Metabolic stress and hypoxia downregulate zincimporter ZnT8 protein with subsequent decrease in the intracellular/ intragranular* Zn concentration. Research group of Liu demonstrated that also ZnT6 and ZnT7 transporters are needed to defend insulin secretion in beta-cells and the insulin storage [2].

\section{$\mathrm{Zn}$ in Insulin}

Pancreatic beta cells have exceptionally high zinc content. Zinc is prerequisit for the hexamerization (ie. three dimer structure of insulin), which is the storage form of insulin (Fig 1.) in the beta-cell granules [3]. But $\mathrm{Zn}$ is also necessary to the transformation from proinsulin to insulin. Therefore to maintain normal function of the production and storage of insulin zinc is indispensible [4].

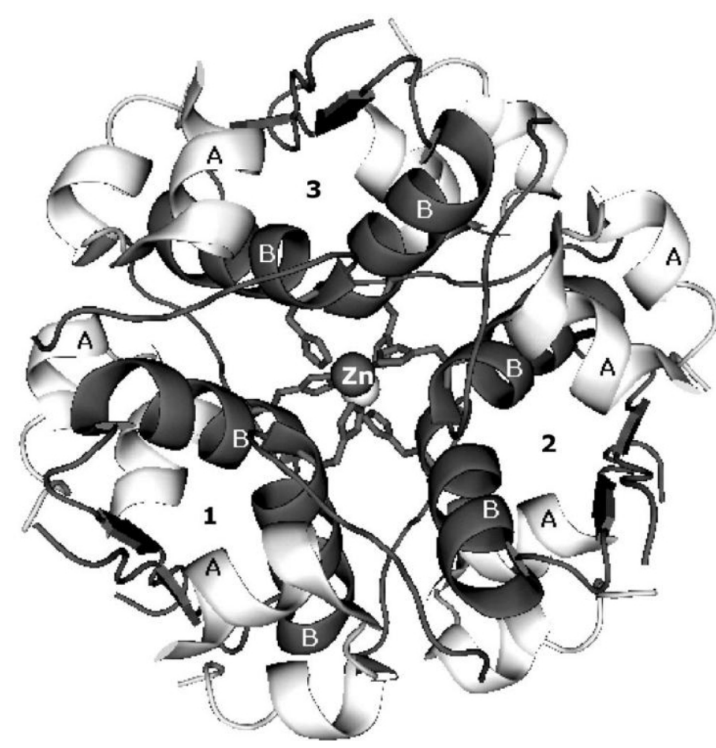

Figure 1. Insulin hexamer with stabilizer $\mathrm{Zn}^{++}$in the middle. 


\section{Insulin Mimetic Function}

Among others also trace elements (eg. vanadium) may have insulin-like properties. In vitro (cell culture) zinc administration is able to activate insulin signaling pathway [5]. Several mechanisms of action were assumed, eg. rat experiments supported that insulin-mimetic actions of zinc are mediated via inhibition of glycogen synthase kinase 3beta. In vivo $\mathrm{ZnO}$ nanoparticles - in mice and rat model - improve glucose tolerance, decrease blood glucose levels, increase expression of DM related gens, eg. that of insulin and insulin receptors', GLUT2 and glucokinase, furthermore elevate blood insulin concentration [6]. $\mathrm{Zn}$ also augment insulin-binding on insulin-receptors.

\section{Modification of Carbohydrate Metabolism}

Zinc hinders carbohydrate absorption by inhibiting alphaglucosidase activiy (direct binding resulting in conformationchange) in the small intestine. The low zinc intake increases glucose utilization in rats [7]. It increases phosphofructokinase and pyruvate kinase enzymes thus support glycolysis and the subsequent lactate production. Zinc overcome the inactivation of pyruvate kinase by glucagon, too. This ion also enhances glucose transport in adipocytes and blocks glycogen synthesis by indirect enzyme inhibition [8]. Noteworthy, Zn improve lipogenesis and support expression of PPARgamma, one of the regulators of fatty acid storage and glucose metabolism, furthermore insulin sensitizer.

*ZnT8 transmembrane protein is essential component of plasma mambrane of insulin secretory granules of pancreatic beta-cells. Its imbalance basically influence beta cell function and may contribute to development of glucose intolerance.

\section{Antioxidant Effect}

In diabetes mitochondria produce more reactive free oxigen radicals which have direct (modification of insulin signaling) and indirect (diabetes-induced complications) effects $[9,10]$. This is one of the hypotheses why use of antioxidants in diabetes is recommended. Zinc exert antioxidant effect in various targets and normalize the in diabetes low levels of glutathion peroxidase, restore catalase and superoxide dismutase activity and activates antioxidant metallothionein sysnthesis [11].

\section{Interactions among the Trace Elements}

Copper administration in rats impairs body gain, diminishes the se-zinc and tissue zinc levels and worsened clinical chemical blood parameters like alkaline phophatase, lactic dehydrogenase and amylase in diabetes as well as in non-diabetes animals. Addition of high dose of zinc to food ameliorates the referred parameters [12]. High doses of zinc hinders absorption of copper. Presence of moderate amounts of iron and iron-fortificated food does not influence significantly the Znabsorption. In contrast, zinc supplementation inprove iron uptake in the diabetic intestine [13]. Zn inhibit N-methyl-D-aspartase (NMDA) receptors therefore $\mathrm{Zn}$ deficit results in increased intracellular Ca-levels [14]. These and other examples demonstrate that the abovementioned bivalent cations are normally in balance and supplementation of the trace elements should be administered simultaneously.

\section{Zinc Supplementation}

The most natural way of zinc intake is food consumption. In general, fruits and vegetables are poor in zinc except potatoes and in less extent green beans and kale. Concentrated dairy products like cheese contains more $\mathrm{Zn}$ and one serving of nuts (cashew, almonds, pine nut) or seeds (especially hemp, flax or pumpkin-seed) is also containing the estimated average requirement of this cation. Best sources from this aspect are red meat (beef, in lower degree lamb, pork) and shellfish (oysters are paticularly high in $\mathrm{Zn}$ but, crab, shrimps, mussels are also very rich in zinc). Zinc content of some groups of food is presented in Table 1. Recommended Daily Allowance (US Institute of Medicine) for zinc is between $8-11 \mathrm{mg} /$ day. It seems in case of zinc deficiency restoration of body zinc content by food intake is difficult.

Table 1. Zinc content of selected foods.

\begin{tabular}{|l|c|c|c|c|c|c|c|c|}
\hline Food & $\begin{array}{c}\text { Cereals (ready- } \\
\text { to-eat) }\end{array}$ & $\begin{array}{c}\text { Shellfish, } \\
\text { mussels }\end{array}$ & Beef, meat & pumpkin seed & $\begin{array}{c}\text { Lamb, } \\
\text { chicken }\end{array}$ & $\begin{array}{c}\text { Cheese } \\
\text { Fruits, fruit } \\
\text { coctail }\end{array}$ & $\begin{array}{c}\text { Milk, dairy } \\
\text { Mushrooms }\end{array}$ \\
\hline $\mathbf{M g} \mathbf{Z n} / \mathbf{1 0 0 g}$ food & $10-30$ & $50-70$ & $6-12$ & 10 & $2-4$ & $3-6$ & $0,5-7$ & $0,3-0,5$ \\
\hline
\end{tabular}

Various attempts have been made to improve $\mathrm{Zn}$-content of staple foods. It seems high $\mathrm{Zn}$-content of soil or $\mathrm{Zn}$-spaying of plants during the growth (biofortification of food) may help in zinc-deficiency on population level.

Zinc absorption takes place mainly in the proximal jejunum and distal duodenum. Absorption from food ranges from 11 to $22 \%$ but absorbed proportion depends on the body $\mathrm{Zn}$-content and the form of zinc as well as on the constituents of the specific food (enhancers and inhibitors) [15]. The high protein-content may rise the $\mathrm{Zn}$-absorption and high $\mathrm{Cu}^{++}$hampers its absorption. These conditions may explain why zinc absorption from the US diet is estimated around 30\% [16]. In contrast, high phytate content of food (phytate: zinc molar ratio
$>$ ca.14) can inhibit zinc intake [17]. The list of high phytate-containing foods are presented in Table 2. The aggregation of zinc deficiency in low-income developing countries supposedly due to regular consumption of high phytate-containing plant-based food [18]. Various pure chemical supplements, like zinc oxide, zinc sulfate, zinc citrate, zinc gluconate, demonstrated an absorption of 49,9-61,3\% in human [19]. Constant cytosolic $\mathrm{Zn}$ concentration is maintained by SLC 30 and SLC39 gene families controlled zinc transporters, named ZnT-s with 10 members and ZIP-s with 14 members, respectively [20]. Zinc transporter gene SLC 30A1 plays a direct role in inorganic zinc (eg. $\mathrm{ZnCl}, \mathrm{ZnSO} 4)$ absorption. The absorption from $\mathrm{Zn}$-gluconate is better than that from $\mathrm{ZnO}\left(\mathrm{C}_{\max }: 18,3 \%\right.$ but not $\left.\mathrm{T}_{\max }\right)$ and also AUC 
was better by $8,1 \%$ [21]. The uptake of organic $\mathrm{Zn}$-compounds (eg. $\mathrm{Zn}$-glycine and $\mathrm{Zn}$-methionine) is less dependent on this transportersystem [22].

Table 2. Phytates in foods.

\begin{tabular}{|l|c|}
\hline \multicolumn{1}{|c}{ Food } & $\begin{array}{c}\text { Phytate content } \\
(\mathbf{m g} / \mathbf{1 0 0 g})\end{array}$ \\
\cline { 2 - 2 } kidney beans & $610-2.380$ \\
\hline peas & $510-1.770$ \\
\hline lentils & $270-1510$ \\
\hline mais & $720-2.200$ \\
\hline wheat (whole) & $390-1.350$ \\
\hline rice & $60-1.080$ \\
\hline peanuts & $170-4.470$ \\
\hline almonds & $650-9.420$ \\
\hline walnuts & $200-6.690$ \\
\hline
\end{tabular}

Dietary supplements usually contain supraphysiologic doses (20$40 \mathrm{mg}$ or more) of zinc in inorganic (oxide compound or chloride/ sulphate salt), or recently rather in organic (eg. Zn-gluconate) form. Or just endogenous vehicles transport $\mathrm{Zn}$ better to the target, like in case of $\mathrm{Zn}$-carnosine. Carnosine is a small, water-soluble endogenous peptide physiologically present in skeletal muscle, brain and nearly every organ. It is prone to form chelates of metals, inclusive $\mathrm{Zn}$ [23].

\section{Clinical Experiences}

Serum zinc is supposed to be low in diabetes patients $[24,25]$. Moreover, the total blood zinc concentration gradually sink in T2DM patients in relation to the duration of diabetes [26]. However Skalnaya reported elevated se zinc level in type 2 diabetes patients in a cohort of 413 postmenopausal women [27]. Zinc concentration in cellular level needs a tight control in order to keep healthy functions. In diabetes even a sin healtly subjects, the $\mathrm{Zn}$-transporters and metallothioneins basicly influence the cellular zinc homeostasis [28]. In a group of pre-diabetes youngsters (between 10-17years of age) se-zinc levels positively correlated with elevated protein intake and negatively correlated with higher carbohydrate intake [29]. The onset of diabetes however is not linked to the zinc levels as describes Park and coworkers based on the results of assesment of toenail-concentration of 3.960 american young population in a periode of 23 years [30].

Meta-analysis of Jayawardena demonstrate beneficial effet of zinc supplementation on glycaemic control [31].The systematic literature survey of de Carvallho demonstrated that plasma zinc levels negatively correlated with glycated hemoglobin percentage (HbA1c) and zinc supplementation tendentiously has ameliorated glycemic control of type 2 diabetes patients [25]. According to the available data zinc is beneficial only for patients having low serum-zinc levels [32]. From the prevention aspect Cochrane evaluation of 2015 conclude to neutral regarding zinc supplementation and insulin resistance (HOMA_IR) as well as major complications like cholesterol and triglyceride levels [33]. The cardiovascular complications are, according to the systematic review of $\mathrm{Chu}$, also not clearly correlat with the zinc status of the T2DM patients [34]. The microvascular complications natheless seems to be $\mathrm{Zn}$-concentration dependent [35]. This is partly due to the antioxidant effect of $\mathrm{Zn}$ as demonstrated Cruz in his summary [36].

\section{Discussion}

Scientific literature of zinc is rich enough however there are few evidences from clinical point of view, ie. randomized controlled studies supporting confident knowledge about the use of zinc supplementation in diabetes mellitus are scarce. Physiological zinc levels in somatic cells are very low but extremly constant. Therefore the presence of stored $\mathrm{Zn}$ and the concerted regulation seems to be essential. If zinc levels in blood were low, symptoms appear slowly and signs usually are aspecific, in this situation supplementation is recommended. In diabetes plasma zinc concentration should be kept within the normal range otherwise insulin-resistance as well as diabetes complications worsen. In case of hypozincemia zinc supplementation improves glycemic control. In prediabetes, when zinc levels are still normal or near normal, supplemental administration of zinc has no beneficial effect. Collectively: if diabetic patient had low zinc concentration, permanent zinc supplementation is needed and should be administered in supraphysiological doses. Contemporary formulations, especially nano-formulations are effective in normalization of zinc homeostasis and dysregulations of diabetes originate in hypozincemia can be corrected by $\mathrm{Zn}$ supplementation.

\section{References}

1. Anderson RA, Roussel AM, FridnD, et al (2001) Potential antioxidantm effects of zinc and chromium supplementation in people with type 2 diabetes mellitus. $J$ Amer Coll Nutr 20: 212-218.

2. Liu Y, Batchuluun B, Ho L, et al (2015) Characterization of zinc influx transporters (ZIPs) in pancreatic betas cells. J Biol Chem 290: 18757-18769.

3. Fu Z, Gilbert ER, Liu D.(2014) Regulation of insulin synthesis and secretion in pancreatic beta cell dysfunction in diabetes. Curr Diabetes Rev 9: 25-53.

4. Fukunaka A, Fujitani Y (2018) Role of zinc homeostasis in the pathogenesis of diabetes and obesity. Int J Mol Sci 19: 467.

5. Norouzi S, Adulcikas J, Sohal SS, Myers S.(2018) Zinc stimulates glucose oxidation and glycemic control by modulating the insulin pathway in human and mouse skeletal muscle cell lines. PloS ONE 13: e0191727.

6. Alkaladi A, Adelazim AM, Afifi M (2014) Antidiabetic activity of zinc oxide and silver nanoparticles on streptozocin-induced diabetic rats. Int J Mol Sci 15: 20152023.

7. Kechrid Z, Demir N, Abdennour C, Bouzerna N (2002) Effect of low dietary zinc intake and experimental diabetes on the zinc and carbohydrate metabolism int he rats. Turk J Med Sci 32: 101-105.

8. Olechnowicz J, Tinkov A, Skalny A, Suliburska J (2018) Zinc status is associated with inflammation, oxidative stress, lipid, and glucose metabolism. J Physiol Sci 68: 19-31.

9. Ullah A, Khan A, Khan I ( 2015) Diabetes mellitus and oxidative stress - a concise review. Saudi Pharmaceut J 24: 547-553.

10. Gerber PA, Rutter GA (2017) The role of oxidative stress and hypoxia in pancreatic beta-cell dysfunction in diabetes. Antioxid Redox Signal 26: 501-518

11. Ranasinghe P, Pigera S, Galappathy P, Katulanda P (2015) Zinc and diabetes mellitus: understanding molecular mechanisms and clinical implications. DARU J Pharmaceut Sci 23: 44.

12. Derouiche S, Kechrid Z (2016) Zinc administration overcomes effects of copper on zinc status cstbohydrate metabolism and some enzyme activities in diabetic and non-diabetic rats. Can J Diabetes 40: 342-347.

13. Barman S, Shrinivasan K (2018) Enhanced intestinal absorption of micronutrient in streptozocin-induced diabetic rats maintained on zinc supplementation. $J$ Trace Elem Med Biol 50: 182-187.

14. Oteiza PI (2012) Zinc and the modulation of redox homeostasis. Free Radic Bio Med 53: 1748-1759.

15. Roohani N, Hurrel R, Kelishadi R, Schulin R (2013) Zinc and its importance for human health: an integrative review. J Res Med Sci 18: 144-157. 
16. Armah SM (2016) Fractional $\mathrm{Zn}$ absorption for men, women and adolescents is overestimated in the current Dietary Reference Intakes. J Nutr 146: 1276-1280.

17. Sandstead HH, Freeland-Graves J (2014) Dietary phytate, zinc and hidden zinc deficiency. J Trace Elem Med Biol 28: 414-417

18. Brown KH, Rivera JA, Bhutta Z, et al. (IZiNCG) (2004) Assessment of the risk of zinc deficiency in populations and option for its control. Food Nutr Bull 25: S99-S203.

19. Wegmüller R, Tay F, Zeder C, et al. (2014) Zinc absorption by young adults from supplemental zinc citrate is comparable with that from zinc gluconate and higher than from zinc oxide. J Nutr 144: 132-136.

20. Bafaro E, Liu Y, Xu Y, Dempski RE (2017) The emerging role of zinc transporters in cellular homeostasis and cancer. Signal Transduct Targeted Ther 2: 17029.

21. Siepmann M, Spank S, Kluge A, et al.( 2005) The pharmacokinetics of zinc from zinc gluconate: a comparison with zinc oxide in healthy men. Int $J$ Clin Pharmacokinet Ther 43: 562-565.

22. Huang D, Zhuo Z, Fang S. et al. (2016) Different zinc sources have diverse impacts on gene expression of zinc absorption related transporters in intestinal porcine eipthelial cells. Biol Trace Elem Res 173: 325-332.

23. Kawahara M, Tanaka K, Kato-Negishi M (2018) Zinc, carnosine, and neurodegenerative diseases. Nutrients 10: 147.

24. Linn CC, Huang YL. (2015) Chromium, zinc and magnesium status in type 1 diabetes. Curr Opin Clin Nutr Metab Care 18: 588-592.

25. de Carvalho GB, Brandao-Lima PN, Maia CS et al. (2017) Zinc's role in the glycemic control of patients with type 2 diabetes: a systematic review. Biometals 30829: $151-162$.

26. Fernandez-Cao JC, Warthon-Medina M, Hall-Moran V et al. (2018) Dietary zinc intake and whole blood zinc concentration in subjects with type 2 diabetes versus healthy subjects: a systematic review, meta-analysis and meta-regression. $J$ Trace Elem Med Biol 49: 241-251.
27. Skalnaya MG, Skalny AV, Tinkov AA. (2017) Serum copper, zinc, and iron levels, and markers of carbohydrate metabolism in postmenopausal women with prediabetes and type 2 diabetes mellitus. J Trace Elem Med Biol 43: 46-51.

28. Chu A, Foster M, Hancock D, et al. (2017) Interrelationship among mediators of cellular zinc homeostasis in healthy and type 2 diabetes mellitus population. $\mathrm{Mol}$ Nutr Food Res 61: 27957812

29. Ho M, Heath AM, Gow M, et al. (2016) Zinc intake, zinc bioavailability and plasma zinc in obese adolescentswith clinical insulin resistance following low energy diets. Ann Nutr Metab 69: 135-141.

30. Park JS, Xun P, Li J, et al. (2016) Longitudinal association between toenail zinc levels and the incidence of diabetes among American young adults: The CARDIA Trace Element Study. Sci Report 6: 23155.

31. Jayawardena R, Ranasinghe P, Galappatthy P et al. (2012) Effect of zinc supplementation on diabetes mellitus: a systematic review and meta-analysis. Diabetol Metabol Syndome 4: 13

32. Ruz M, Carrasco F, Sanchez A, et al. (2016) Does zinc really „,metal” with diabetes? The epidemiologic evidence. Curr Diab Rep 16: 111.

33. El Dib R, Gameiro OL, Ogata MS et al. (2015) Zinc supplementation for the prevention of type 2 diabetes mellitus in adults with insulin resistance. Cochrane Database Syst Rev 5: CD005525.

34. Chu A, Foster M, Summan S. (2016) Zinc status and risk of cardiovascular diseases and type 2 diabetes mellitus - a systematic review of prospective cohort studies. Nutrients 8: 707.

35. Luo YY, Zhao J, Han XY, et al. (2015) Relationship between serum zinc level and microvascular complications in patients with type 2 diabetes. Chin Med J 128: 3276-3282.

36. Cruz KJC, de Oliveira ARS, Marreiro DN (2015) Antioxdant role of zinc in diabetes mellitus. World J Diabetes 6: 333-337.

Citation:

Télessy IG (2019) Zinc Supplements - Any Benefit in Diabetes?. Endocrinol Diabetes Metab J Volume 3(4): 1-4. 